\author{
Military Technical College \\ Kobry El-Kobbah, \\ Cairo, Egypt.
}

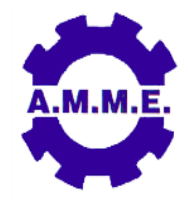

\section{OPTIMIZATION OF SHAPE MEMORY EFFECT IN FE-BASED SHAPE MEMORY ALLOYS BY MODIFICATION OF SOLUTION TREATMENT \\ TEMPERATURE}

\author{
M. K. El Fawkhry ${ }^{1}$, V. Sampath ${ }^{2}$ and T. Mattar ${ }^{3}$
}

$18^{\text {th }}$ International Conference

on Applied Mechanics and Mechanical Engineering.

\begin{abstract}
Solution treatment is an important process parameter in the context of thermo mechanical processing of shape memory alloys. It is one of the preliminary steps that is required to obtain martensite in the alloys. As far as martensite is concerned, it forms the basis of shape memory effect as shape memory alloys are used capitalizing on their unique properties of shape memory effect and superelastic effect. It is well known that the grain size of austenite in the solutionized condition depends on the austenitizing/solutionizing temperature. Moreover, the solution treatment temperature influences the transformation temperatures of SMAS. It has been found by researchers that solutionizing temperature brings about modification in the grain size, the grain boundary angles, and the annealing twins. The major objective of the present work is to assess the influence of modifications in the microstructural features brought about increasing/decreasing the solution treatment temperature. Optical microscopic and back scattered electron diffraction studies reveal the microstructural changes brought about by changing the solutionizing temperature. The X-ray diffraction experiments reveal the increase in SIEM in the alloy that was solution treated at $800,900,1000^{\circ} \mathrm{C}$.
\end{abstract}

The TEM studies reveal the formation of stacking faults and their interaction with one another and also with the grain boundaries. The results indicate that solutionizing at an optimal temperature of $1000^{\circ} \mathrm{C}$ leads to increased shape recovery strain as well as shape recovery stress. The results are presented and discussed in the paper.

\title{
KEYWORDS
}

Shape memory alloy, Iron based shape memory alloy, Solution treatment, Shape memory effect, Stress recovery.

1,3 Central Metallurgical and Research and Development Institute (CMRDI), Cairo, Egypt. Email of corresponding author: mohamed.elfawkhry@gmail.com

2 Department of Metallurgical and Materials Engineering, Indian Institute of 


\section{INTRODUCTION}

Fe-Mn-Si-based shape memory alloys have been studied quite extensively over the past several decades since Sato et al. [1] discovered a good shape memory effect in a Fe-30Mn-1Si (here after all the compositions are in mass\%) single crystal alloy in the early 1980s. The shape memory effect was then reported in Fe-(30-32) Mn-6Si polycrystalline alloys by Murakami et al. [2]. The shape memory effect in the Fe-MnSi-based shape memory alloys is associated with the stress-induced martensitic transformation from _ (fcc) austenite to _ (hcp) martensite, and its reversion by subsequent heating [3-6]. These alloys are suitable for constrained recovery applications due to their one-way shape memory effect [7]. The Fe-28Mn-6Si-5Cr alloy has recently been used for pipe joints [8] and rail couplings [9] due to the good combination of the shape memory effect, mechanical properties and corrosion resistance. However, the applications of this alloy have been limited due to its relatively small shape recovery strain. One of the most important factors that can be adopted to improve the shape memory effect is the morphology of the primary austenite phase that is completely dependent on the solution treatment in term of temperature and holding time. In this research the adopting of the primary austenite was carried out by varying the solution treatment temperature at constant holding time. Thereafter, the characteristic properties of Fe- Mn- Si shape memory alloy were monitored to adjust the optimum solution treatment temperature.

\section{EXPERIMENTAL WORK}

The alloys were melted in an open air induction furnace under an argon atmosphere for producing Fe-Mn-Si based iron shape memory alloy with nominal compositions $0.05-0.1 \% \mathrm{C}, 29-31 \% \mathrm{Mn}, 4-5.5 \% \mathrm{Si}$, Bal\%Fe. The molten alloy was poured into a preheated $(400 \circ \mathrm{C}, 1 \mathrm{~h})$ mild steel mould. Five moulds were produced, adhering to the desired composition of Fe-Mn-Si shape memory alloy. The mean composition of the produced ingots is given in Table 1. The produced ingots were subjected for hot rolling to produce sheets of $1 \mathrm{~mm}$ thickness. The hot rolling was carried out at $1100^{\circ} \mathrm{C}$. Samples were cut from the rolled sheets were prepared according to the dimensional requirement for DSC, bend test, microstructure, XRD, and tensile test. However, samples were machined /cut by EDM. Five different annealing temperatures were selected to identify the role of solution treatment temperature on the microstructure, and the shape memory effect of the alloys studied. Microstructural observations are widely used in characterizing shape memory alloys to detect the transformation of austenite to martensite, and the reverse transformation, optically. On the other hand, the grain size of austenite, as well as the annealing twins might have acted as important parameters on the shape memory effect of Fe-Mn-Si based iron shape memory alloy. Therefore, the samples of as cast, as rolled, as solution treated conditions were prepared by grinding on SiC emery papers with grit size varying between 180 and 3000, followed by polishing, and then etching by using $5 \%$ nital. The shape recovery was examined using the conventional bend test. A range of pre-strains was given to the sheet samples by bending them around round form to attain a definite prestrain $3.1 \%$. The pre-strain $\varepsilon$ was taken as the maximum tensile/compressive strain, and was determined by Equation (1): 
$\varepsilon_{\mathrm{r}}=\varepsilon-\varepsilon_{\text {res }}$

(n) Shape recovery ratio $=\varepsilon-\varepsilon_{\text {res }} \varepsilon^{*} 100$

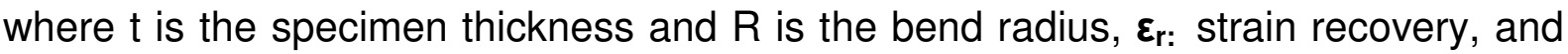
$\varepsilon_{\text {res: }}$ reserved strain after annealing.

Table 1 The chemical composition of the produced alloy.

\begin{tabular}{|c|c|c|c|c|c|c|c|c|}
\hline \multirow{2}{*}{ Heat No. } & \multicolumn{8}{|c|}{ Chemical composition, wt \% } \\
\cline { 2 - 10 } & $\mathbf{C}$ & $\mathbf{M n}$ & $\mathbf{S i}$ & $\mathbf{C r}$ & $\mathbf{S}$ & $\mathbf{P}$ & $\mathbf{C a}$ & $\mathbf{F e}$ \\
\hline MSO & 0.11 & 29 & 5.1 & 0 & 0.0003 & 0 & 0 & bal \\
\hline
\end{tabular}

\section{RESULTS AND DISCUSSION}

\section{Differential Scanning Calorimetry (DSC)}

The result from the differential scanning calorimetry experiments reveals that the transformation temperatures are closer to the values quoted in an earlier publication. The significant transformation temperatures by using DSC were determined as given in Fig.1. It was noticed a large fluctuation in the transformation temperatures, resulting from the change in the solution treatment temperature.

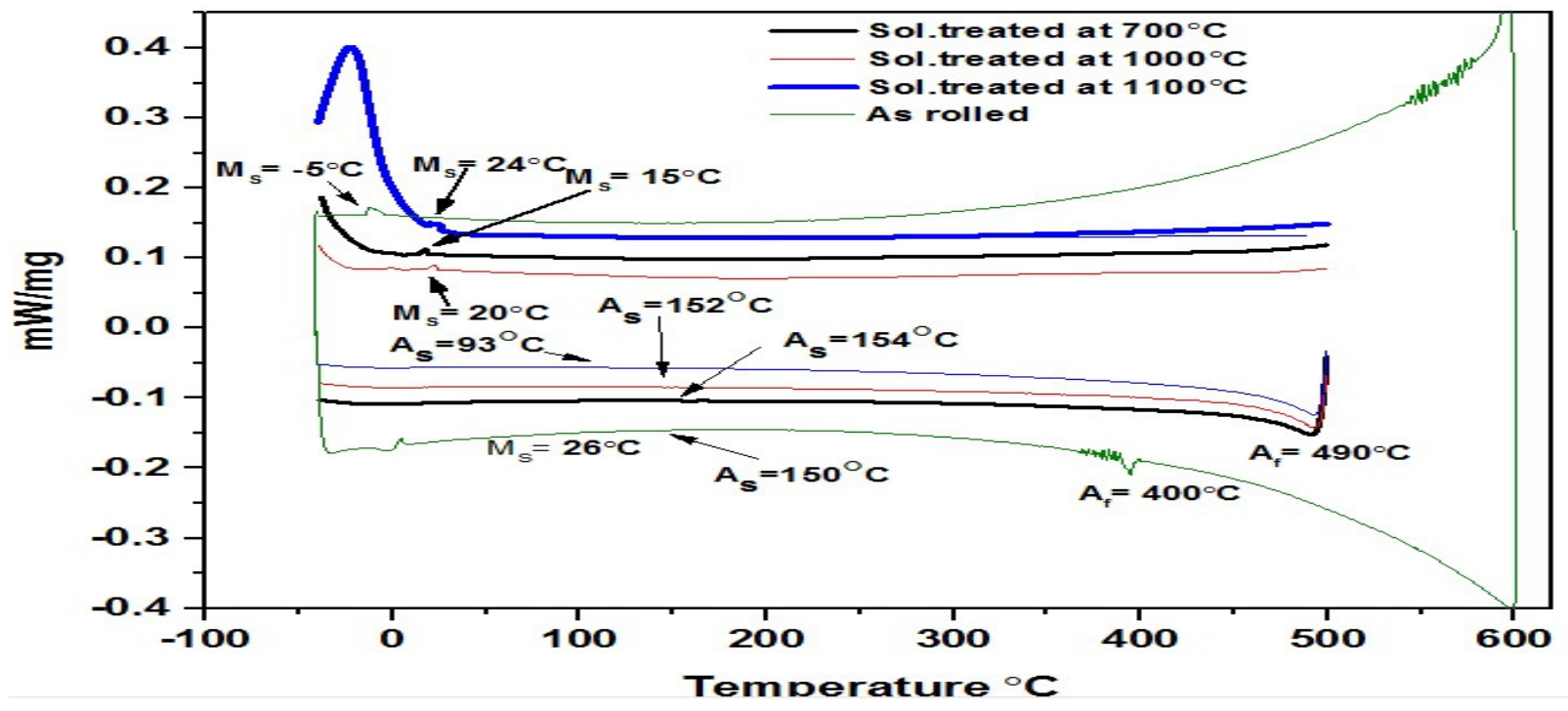

Fig.1 DSC plot for Iron-Based shape memory alloy in as rolled condition, and after solution treatment at $700,1000,1100^{\circ} \mathrm{C}$.

\section{Shape Memory Effect (SME)}

The shape recovery ratio $\eta$ was determined using Equations (2) and (3). The samples after bend test and annealing at $6000 \mathrm{C}$ are shown in Fig.2. On the other hand, the variation of SME of the samples tested after different solution treatment temperatures is shown in Fig. 3. It is assured through the calculation of shape memory effect of the samples bent that the optimum solution treatment temperature is $1000^{\circ} \mathrm{C}$. However, the less shape memory effect was observed either at 700 and/or $1100^{\circ} \mathrm{C}$. 


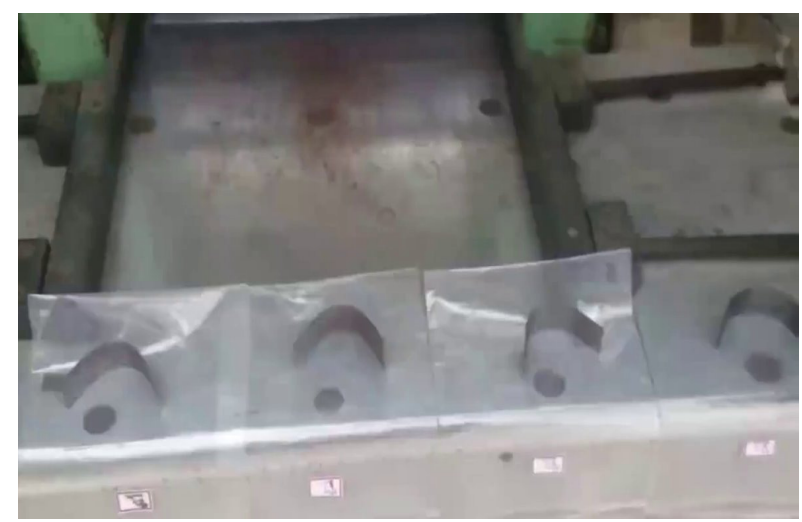

a. The samples shown after bending at certain pre-strain $3.1 \%$.

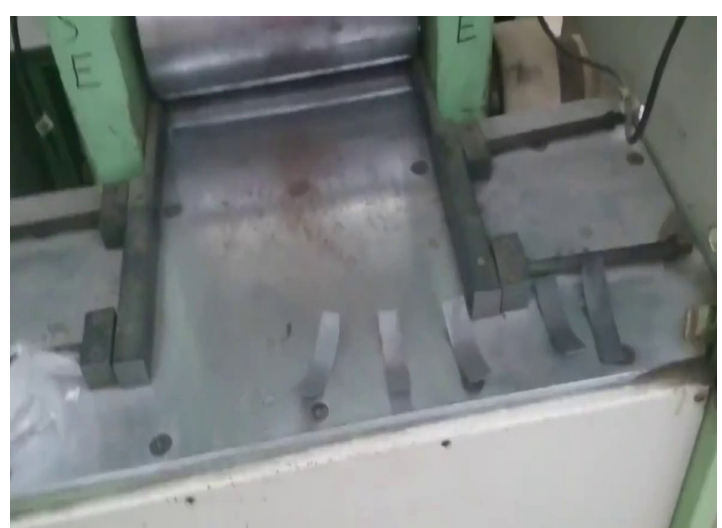

b. Bend samples after annealing at $600^{\circ} \mathrm{C}$.

Fig. 2 Bent samples before and after subjecting to the annealing treatment at $600^{\circ} \mathrm{C}$.

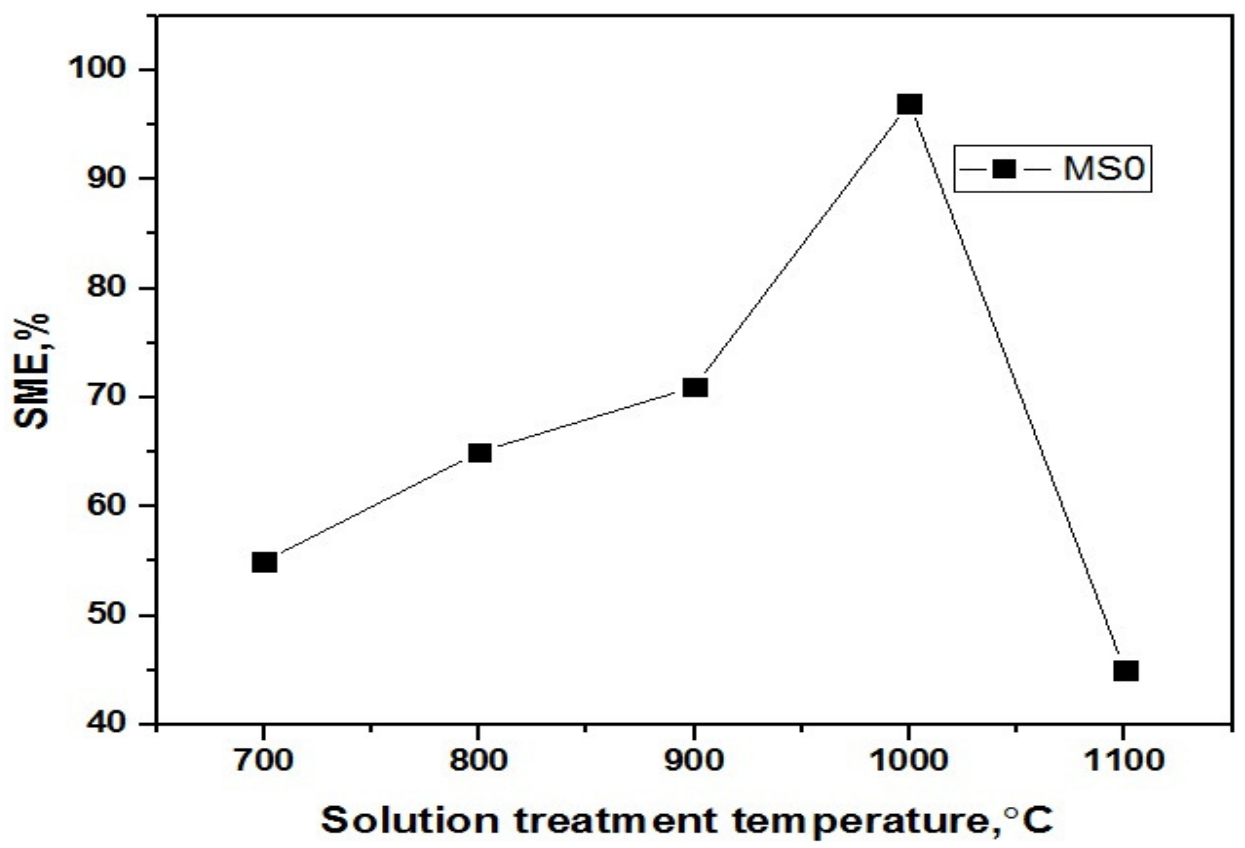

Fig. 3 The effect of solution treatment temperature on SME of MS0 after pre-strain $3.1 \%$.

\section{Monitoring the Phase Transformation through SME Test}

The generated phases after bending test and after recovery annealing at $600^{\circ} \mathrm{C}$ were identified optically by optical microscope, and by using X-ray diffractometer with $\mathrm{Cu}$ radiation source. The investigated $\mathrm{Fe}-\mathrm{Mn}$-Si shape memory alloys were pre-strained by $3.1,6.5 \%$, and thereby they were recovery annealed at $600^{\circ} \mathrm{C}$. Then, SIEM (stress induced eipslon martensite) was determined after the bending test and its reverse transformation after annealing recovery.

\section{Bending at $3.1 \%$}

\section{- Microstructure observations}

The microstructure of Fe-Mn-Si shape memory alloys were optically observed by 
optical microscope after bending at $3.1 \%$ and recovery annealing as shown in Fig.4. The grain size and annealing twins were observed as the main powerful factors on promoting the induced phases either SIEM, or a martensite. As decreasing the fraction of annealing twins, the enrichment in SIEM was observed [10].
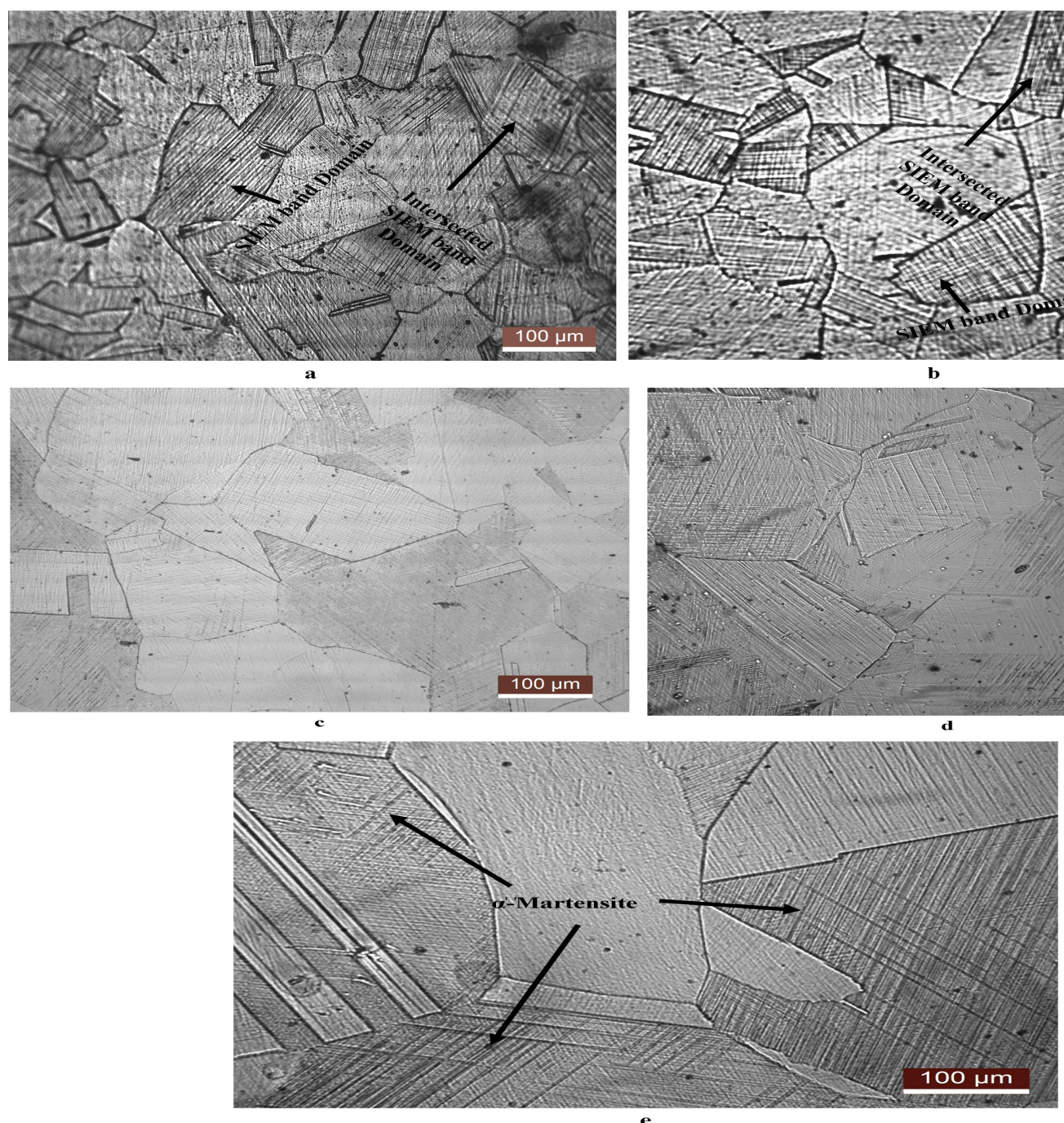

a. solution treated at $700^{\circ} \mathrm{C}$, b. solution treated at $800^{\circ} \mathrm{C}$, c. solution treated at $900^{\circ} \mathrm{C}$, d. solution treated at $1000^{\circ} \mathrm{C}$ and e. solution treated at $1100^{\circ} \mathrm{C}$

Fig. 4 The microstructure of Fe-Mn-Si shape memory alloy after bending by pre strain $3.1 \%$ and recovery annealed at $600^{\circ} \mathrm{C}$.

\section{- XRD observations}

X-ray diffraction of Fe-Mn-Si shape memory alloy after bending $2.5 \%$, and after recovery annealing proves the generation of SIEM, and $\alpha$-martensite in accordance to the solution treatment temperature. 


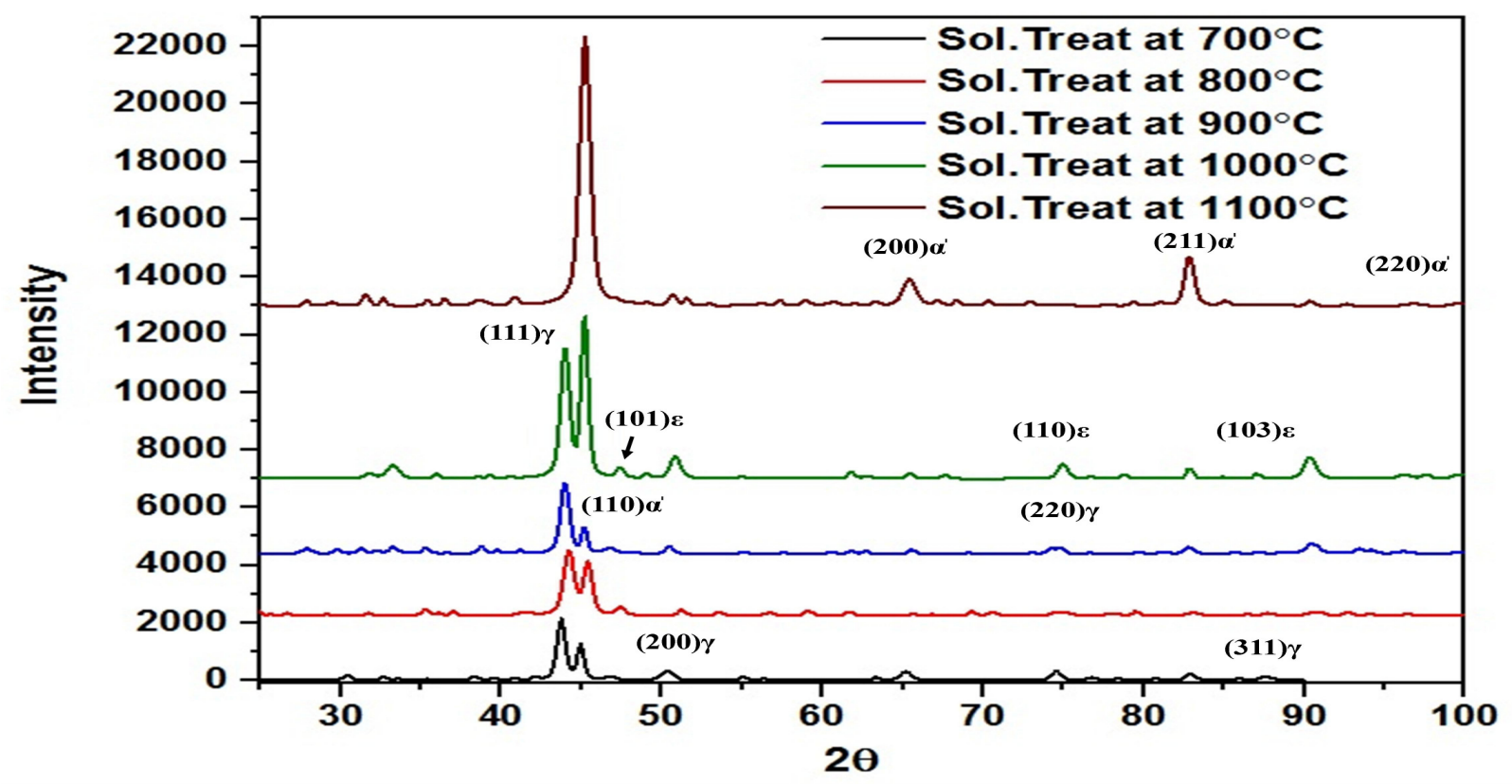

Fig. 5 XRD profile of the investigated Fe-Mn-Si shape memory alloy after bending by $3.1 \%$ pre-strain.

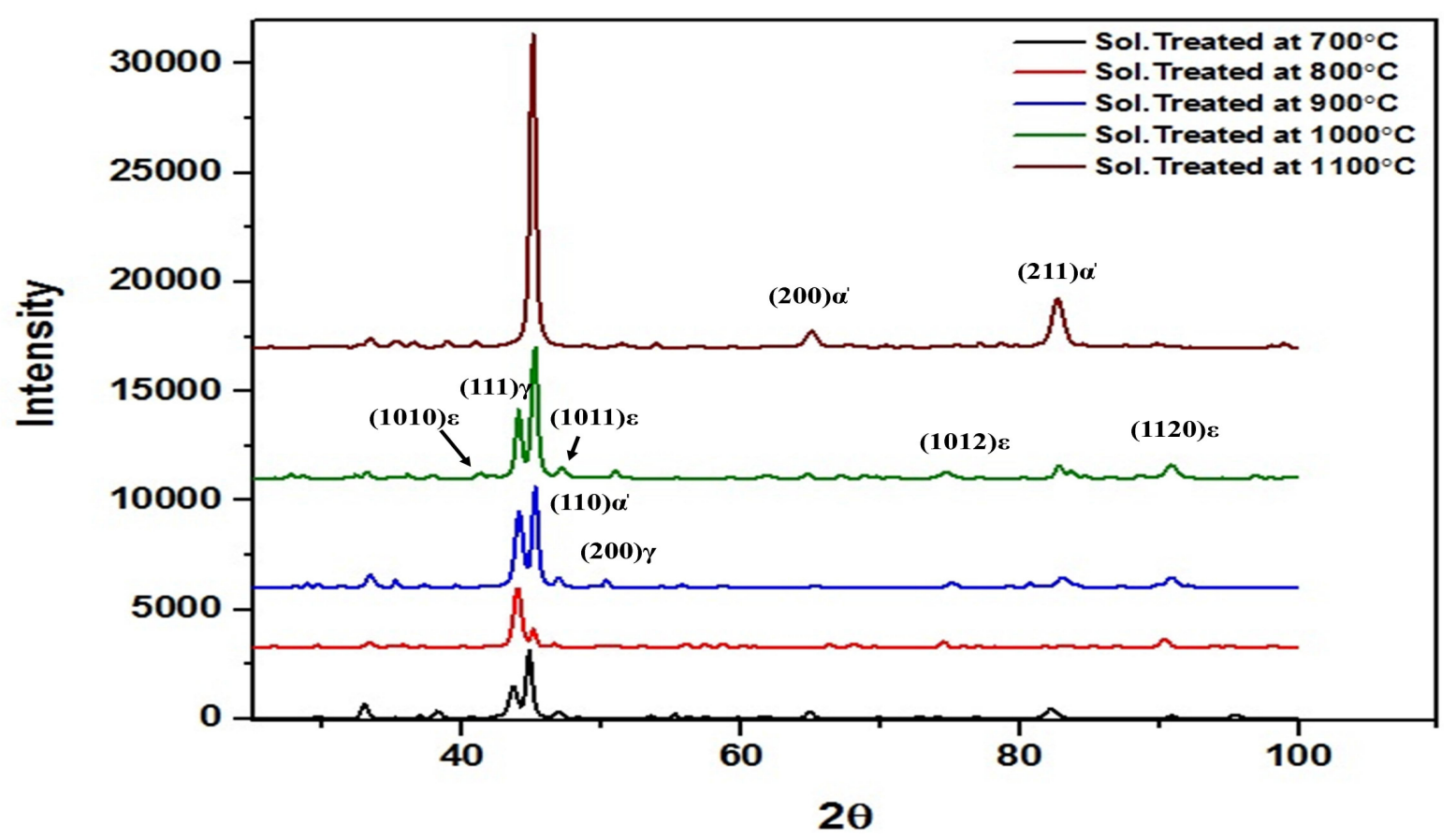

Fig. 6 XRD profile of the investigated Fe-Mn-Si shape memory alloy after bending by $3.1 \%$ pre-strain, followed by recovery annealing at $600^{\circ} \mathrm{C}$.

\section{Bending at $6.5 \%$}

- Microstructure observations

The microstructure of Fe-Mn-Si shape memory alloys were optically observed by 
optical microscope after bending at $6.5 \%$ and recovery annealed at $600^{\circ} \mathrm{C}$ as shown in Fig. 8.
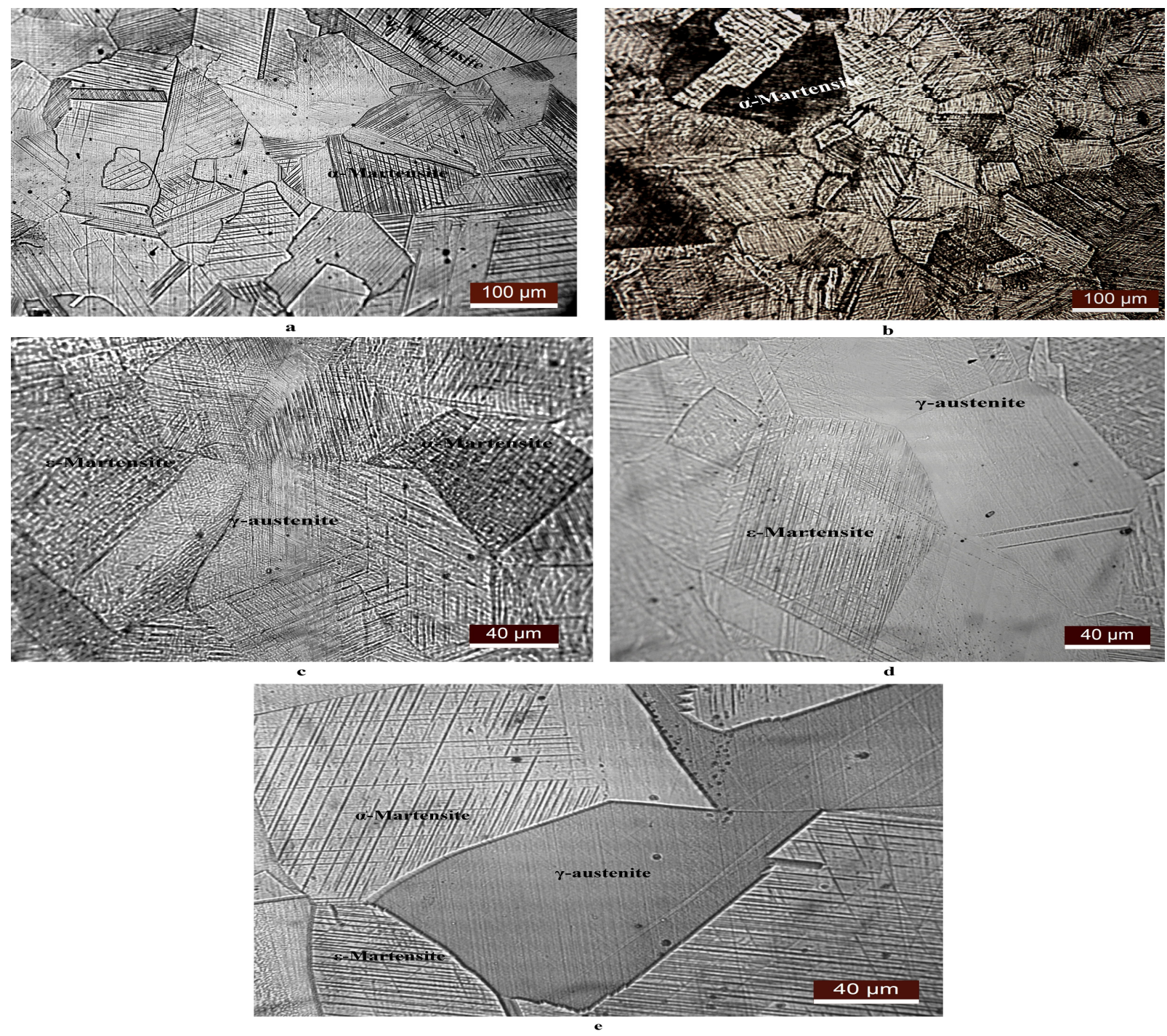

a. solution treated at $700^{\circ} \mathrm{C}$, b. solution treated at $800^{\circ} \mathrm{C}$, c. solution treated at $900^{\circ} \mathrm{C}$, d. solution treated at $1000^{\circ} \mathrm{C}$, e. solution treated at $1100^{\circ} \mathrm{C}$.

Fig. 7 The microstructure of Fe-Mn-Si shape memory alloy after bending by pre strain $6.5 \%$ and recovery annealed at $600^{\circ} \mathrm{C}$.

\section{- XRD observations}

X-ray diffraction of Fe-Mn-Si shape memory alloy after bending 6.5\%, and after recovery annealing proves the generation of SIEM, and $\alpha$-martensite in accordance to the solution treatment temperature. At $1000^{\circ} \mathrm{C}$, the significant peak of SIEM is observed in respective to the other solution treatment temperatures. These observations assure the results that were detected optically. 


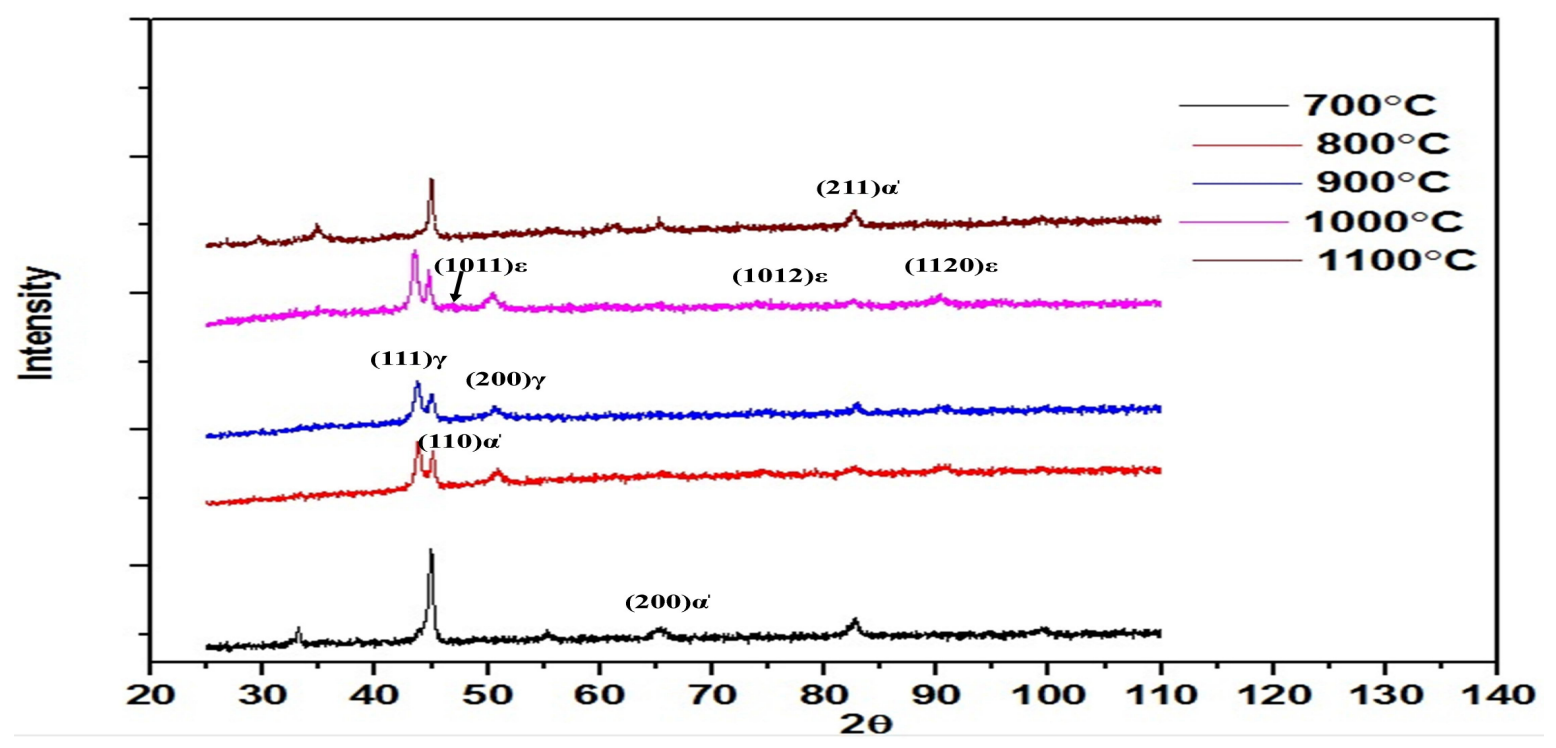

Fig. 8 XRD profile of the investigated Fe-Mn-Si shape memory alloy after bending by $6.5 \%$ pre-strain.

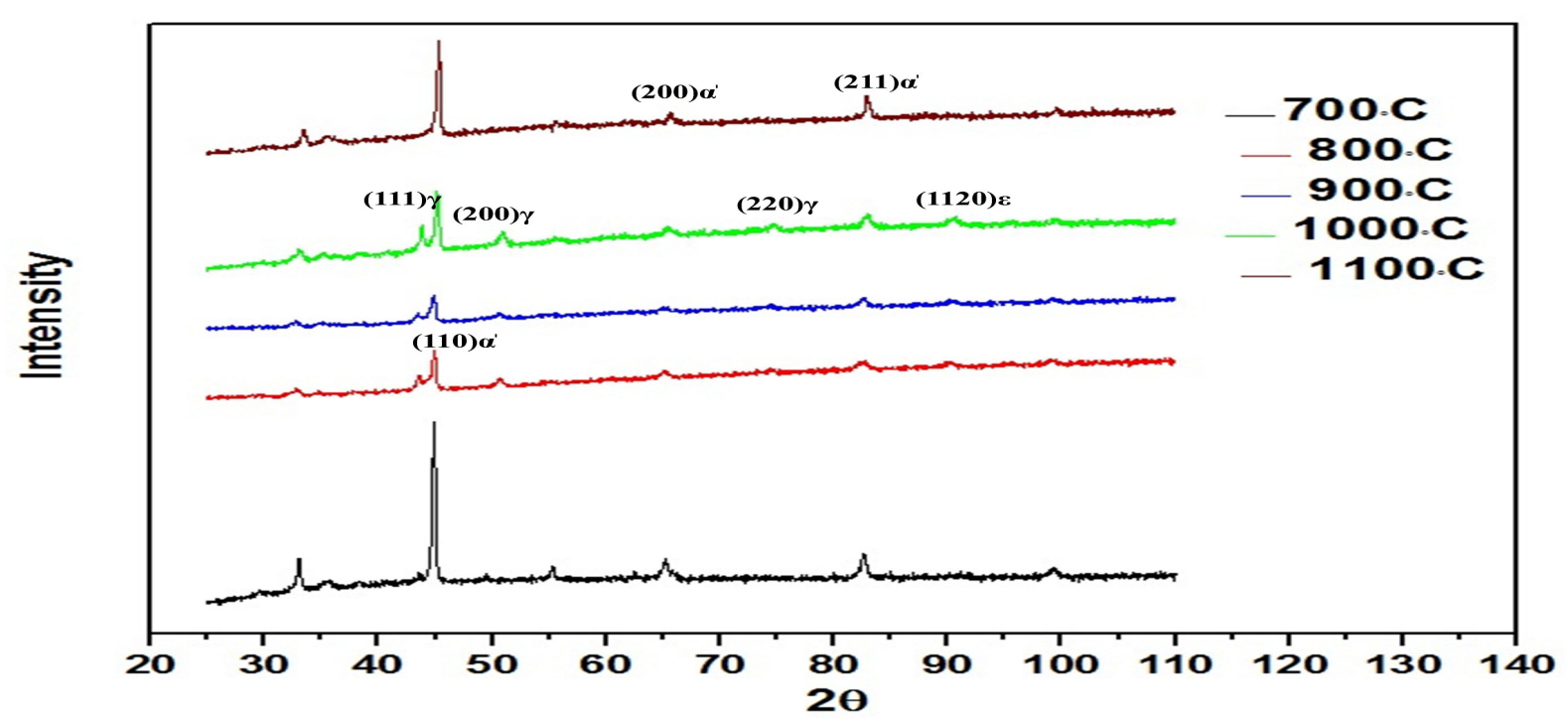

Fig. 9 XRD profile of the investigated Fe-Mn-Si shape memory alloy after bending by $6.5 \%$ pre-strain, followed by recovery annealing at $600^{\circ} \mathrm{C}$.

\section{CONCLUSIONS}

- The solution treatment has a great impact on the characteristic properties of FeMn-Si based iron shape memory alloy.

- Solution annealing at $1000^{\circ} \mathrm{C}$ reform the austenite structure with low fractions of annealing twins.

- The deterioration in strain recovery is clearly observed at $1100^{\circ} \mathrm{C}$ as a result of grain growth. 


\section{REFERENCES}

[1] A. Sato, E. Chishima, K. Soma, T. Mori, Acta Mater. 30 (1982) 1177-1183.

[2] M. Murakami, H. Otsuka, H.G. Suzuki, S. Matsuda, Proceedings of the International Conference on Martensitic Transformations (ICOMAT-86), 1986, pp.985-990.

[3] A. Sato, K. Soma, T. Mori, Acta Mater. 30 (1982) 1901-1907.

[4] A. Sato, E. Chishima, Y. Yamaji, T. Mori, Acta Mater. 32 (1984) 539-547.

[5] A. Sato, T. Mori, Mater. Sci. Eng. A 146 (1991) 197-204.

[6] L. Jian, C.W.Wayman, Scripta Mater. 27 (1991) 279-284.

[7] M. Sade, K. Halter, E. Hornbogen, J. Mater. Sci. Lett. 9 (1990) 112-115.

[8] T. Maruyama, T. Kurita, Kinzoku 74 (2004) 160-163.

[9] A. Sato, H. Kubo, T. Maruyama, Mater. Trans. 47 (2006) 571-579.

[10] Wang, Gaixia, et al., Smart Materials and Structures 25.7 (2016): 075013. 